\title{
Rethinking the Bangladesh State
}

\author{
David Lewis ${ }^{1}$ and Willem van Schendel ${ }^{2}$
}

Abstract:

The study of the Bangladesh state continues to be a path less travelled for scholars of South Asia. The articles in this special issue aim to offer fresh perspectives based on recent ethnographic work on a variety of aspects of the state by new young national and international scholars. Overall, there is a pressing need to pay closer attention to the state and to think about it in new ways, and in this brief concluding article we offer some thoughts on where we are and some pointers towards where we may need to go. While there are many strengths to the small quantity of literature that exists on this theme, there are also some important limitations.

Keywords:

Bangladesh state, ethnographic studies, accidental ethnographies, research agenda.

\section{The need for a theory of the BD state. How existing views fall short.}

Much of what has been written on the Bangladesh state remains trapped within dominant nationalist narratives. Accounts tend to emphasise events of 1971 but obscure the importance of the longer time frame during which the Bangladesh state has taken its shape (Kamal, 2009; Van Schendel, 1995). While recognising the importance of 1971, we cannot understand today's state without paying attention to roots that stretch much further back to the Mughal, British and Pakistan periods, for example in the evolution of structures of local government (Siddiqui, 1994). A related problem is an enthusiasm in accounts of the state for emphasising key moments of action, hope or despair. This tends to produce an episodic bias in which a primary focus on significant events, such as the assassination of Sheikh Mujib in 1975, or the Shahbag protests of 2013, means that less attention is paid either to underlying patterns, or to more humdrum aspects of statehood, such as the daily experiences of ordinary people as they encounter the local state in its service-providing role (Lewis and Hossain 2019; Hossain 2010). There is a need for more ethnographic studies that can engage with less dramatic but equally important state 'stories'.

A second issue is that while there has been regular interest in the state among development scholars, this has often been limited to an institutionalist focus influenced by political science and political sociology that has primarily sought to explain problems of 'governance', 'corruption' or 'civil society' (e.g. Mushtaq Khan, 2014; Wood 2018). There are also regular references in development literature to Transparency International's corruption index in

\footnotetext{
${ }^{1}$ London School of Economics and Political Science. https://se.academia.edu/DavidLewis.

${ }^{2}$ University of Amsterdam. https://uva.academia.edu/WillemVanSchendel.
} 
discussions about the state (e.g. BRAC 2006), or to the narrative of the 'surprise' of the country's strong economic growth despite its governance problems (e.g. Mahmud et al, 2004). While such approaches can of course be valuable, they are open to the criticism that the state is being evaluated against Western liberal norms. Such approaches may also fall prey to the related criticism that they are primarily driven by normative developmentalist frameworks that characterise the state as 'failed' or 'fragile', but which do not in the end tell us very much about how it actually works. Tendencies towards reductionism are at odds with the idea that the state, as Sharma and Gupta (2006: 6) have described it, is 'a multilayered, contradictory, trans-local ensemble of institutions, practices, and people' that can only be fully captured through the use of multiple approaches and methodologies.

A third problem is that the study of the Bangladesh state is limited by a narrow territorial focus within its borders, without due attention paid to the state's international dimensions. For example, newer work shows how the state is projected into international humanitarian arenas through the rapid growth of its UN peacekeeping role overseas (see e.g. Kieran Mitton's account of how Sierra Leoneans have come to imagine and identify Bangladesh through contact with the army in its peacekeeping). At the same time, understandings of the state are highly centralised, with the normal assumption being that what matters in Dhaka is what counts. When people talk about the state, they usually ignore the state in the Chittagong Hill Tracts (CHT), just as in India generalisations that are made about the state tend to ignore northeast India.

Finally, conditions of knowledge production have also limited our accounts of the state. Much of the writing about the Bangladesh state produced since 1971 has rested on a narrowly 'applied' type of social science research, usually underpinned by foreign donor commissioning, in which normative agendas are uppermost and critical writing is generally discouraged. Despite the decline in the role and influence of foreign aid today, the current domestic political climate is one that increasingly constrains critical writing, with a number of recent attacks on university based academics. Writing about the state may be regarded by local researchers as simply too dangerous an activity to think about undertaking in a fully objective way.

So how should we begin this rethinking of the state in Bangladesh? The approach taken by the editors and many of the contributors to this volume is to view the study of the state as a relatively 'new field' that requires identification of new analytical starting points and the rejection of some old ones. For example, while we recognise the regional historical and geographical continuities that have informed the development of the Bangladesh state, we do not necessarily see the Indian or Pakistani states as productive starting points for comparison given their divergent trajectories. We also commend the efforts of contributors to avoid the pitfall of treating what happens in Dhaka as a proxy for understanding the state as a whole by instead presenting different perspectives drawn from 'middle Bangladesh' (e.g. Ruud, Kuttig, and Schulz, this volume). 
The use of ethnographic approaches assumes and draws attention to the fact that the state is not unitary, simple, or known, and recognises that we are only just beginning to understand it. Each of the articles here offers a different way of approaching the 'elephant in the room' in the sense of trying to imagine its dimensions, by approaching it from the perspective of 'the local'. The insights that emerge are persuasive because they each present different contours of the state and help build a perspective that draws primarily from people's experiences and perceptions. This approach rejects the tendency to see the state in simple, unitary terms, but acknowledges the importance of seeking to identify and understand its patterning. For example, the various components of the state - party, police, army, bureaucracy, judiciary are interconnected elements of the state but they also need to be approached and analysed separately. Doing this enables us to get to grips with the ways that the state is imagined into a unified whole by different social actors. In this way, new parts of the elephant are revealed.

\section{An ethnographic approach.}

The introduction to this special issue rightly makes the claim that ethnographic perspectives on the state offer important new insights. Ethnography has a number of strengths. It involves face-to-face contact between scholar and interlocutor, thereby giving voice to individual Bangladeshis and highlighting how they understand the state and its historical development. These understandings may be very different from scholarly assumptions - ethnographers speak of 'emic' and 'etic' perspectives - and are essential to comprehend how Bangladeshis think about their state, and how they deal with it. The ethnographic confrontation can produce a powerful corrective to the historical models and theories of the state that social scientists bring to their research. Ethnographers constantly need to re-examine their presumptions in light of what their interlocutors bring to the research.

The ethnographic approach offers the possibility of more powerful analyses through using local expressions such as mohol (Ruud, this issue) to explore the state and develop a glossary of local terms from which to build larger conceptual frameworks. For example, can we understand politics at the apex of the Bangladesh state better by looking at them through the prism of rural politics? The topography of the deltaic landscape has led to dispersed homesteads and small hamlets, not tightly organised communities under a single village head. Rural politics are dominated by continually shifting alliances of family and hamlet leaders (matbors). Such flexible alliances also characterise the national parties that dominate the state's highest echelons (Lewis 2011, 75-107). Could we usefully liken the country's top politicians to rural matbors struggling to keep their alliances alive?

Ethnography provides an opportunity to engage in far more depth with how people think about their state and its history, but it has some limitations. It offers very detailed, sensitive and revealing vignettes of the state but these are necessarily fragmentary, so it may be difficult to join them up. In addition, ethnography provides a 'snapshot' of the state in action that tends to be ahistorical and flat in terms of time perspectives.

A useful way to address this latter problem is to return to earlier ethnographic or 'accidental ethnographic' accounts. There are a surprising number of sources for this, many of which are 
not widely enough known. Ethnographic approaches to the state in eastern Bengal are hardly new. A full review of earlier accounts is well beyond the scope of this article, but we can point to various types of accounts that can be helpful. There have always been keen observers of the local workings of the state, and many have left accounts of their impressions. Their writings are a valuable resource for ethnographers today because they help us place current events in their historical context.

Autobiographies can be useful 'accidental ethnographies' of the state. Among the published ones describing the colonial state in eastern Bengal are observant officials Lewin (1912) and Beames (1951) on the late-nineteenth century, and official's wife Mazumdar (1977) and writer Chaudhuri (1951) on the early twentieth century. Personal diaries are also full of insights about the state, for example, indigo factory manager John Machell's journals (184650), or Comilla agriculturalist Ali's (2011) diaries of the 1920s to 1940s. In addition, the British colonial period is very rich in reports by touring officials (e.g. Buchanan in Dinajpur (1833) and southeastern Bengal (1992)) and official documents, for example the Report of the Indigo Commission, which contain many interviews with cultivators, officials and observers (Report 1860-61). There is also a wealth of district-level records as well as reports that contain ethnographic material on the state, from the Survey and Settlement Reports (carried out between 1888 and 1940) to District Gazetteers, Wise's (1883) book on Dhaka and Jack's (1916) on Faridpur. Much of this material has been preserved in the National Archives of Bangladesh in Dhaka. Historians of Bangladesh such as Kamal (2009), Iqbal (2010) and Ali (2018) have used such material, as well as oral history (Iqbal 2018), and their insights into the workings of the state can be read with an ethnographic eye.

Another way is to connect with prior professional ethnographic research, which began to be practised in the region that is now Bangladesh in the 1940s. For overviews, see Adnan (1989), Saqui and Akhtar (1987), and Rashid and Shafie (2017). Mukherjee's (1971) study of six villages in Bogra between 1942 and 1946 was a landmark. It heralded a rapid expansion of ethnographic knowledge production during the 1950s and 1960s. Some of the classic studies of this period, when Bangladesh was known as East Pakistan, are Den Hollander (1955/1990), Qadir (1960), Bessaignet (1960), Hara (1991), Owen (1962), Bernot (1967), Bertocci (1970), Ellickson (1973), Zaidi (1970) and Mey (1980).

After Bangladesh attained independence in 1971, the field of ethnographic studies saw an abrupt expansion. Many of these ethnographies had much to say about the state, even though most did not specifically focus on it. Some influential early examples are Thorp (1978), Jahangir (1979), BRAC (1979; 1980) and Hartmann and Boyce (1983). An important development was the emergence of ethnographic re-studies, e.g. Arens and Van Beurden (1977) and Arens (2014); Van Schendel (1981/82); Westergaard (1985) and Westergaard and Hossain (2005); Jansen (1986 and 2019); and Siddiqui (2000). These studies provided a window on change between two ethnographic snapshots in time. It is worth noting that fewer village ethnographies have been written in recent decades, but urban ethnographies became more common. An example is Zaman's (2005/2017) study of a government hospital in Chittagong. 
In other words, the ethnographic method is not new in Bangladesh and it has never been solely the preserve of anthropologists. Current practitioners could benefit from comparing their work with that of their precursors, as well as historians. They must also learn from points that critics have raised. For example, Orr (2012: 1580) warns against the urge to generalise and argued that ethnographic studies of the Green Revolution in Bangladesh 'produced facts that could neither prove nor disprove claims about what was happening at the national level'. Ethnographers should be willing to challenge their own scholarly and ideological persuasions, including their conviction that ethnographic research is necessarily superior to large-scale quantitative methods.

\section{The timeliness of the search for fresh perspectives.}

This is a good time to embark on a re-examination of the Bangladesh state. We are witnessing an important generational shift. First, in considering the history of knowledge production in Bangladesh it is essential to keep in mind that this is a society whose intellectual elite has been decimated not once, but three times. The partition of British India and the birth of Pakistan in 1947 saw the flight of numerous intellectuals, who happened to be Hindus, to India. The 1950s and 1960s witnessed the gradual emergence of a homegrown intelligentsia in competition with non-Bengali immigrant intellectuals. This competition ended tragically with the Bangladesh Liberation War of 1971. Non-Bengali intellectuals either fled to West Pakistan or got killed. The homegrown intelligentsia was decimated as a result of targeted killings by the Pakistan army and allied vigilante groups. Bangladesh came into being with a tiny, traumatised elite.

Second, in the impoverished circumstances of the 1970s and 1980s this elite consolidated its position mainly using international donor funds. Very few Bangladeshis could gain access to a foreign education at the time, and this forms a striking contrast to elite families in India and Pakistan (who had since the colonial period travelled to leading UK universities for advanced degrees, including in anthropology). The type of research that local researchers could undertake was hampered by their weak background in theory and methodology, as well as by the fact that there was little or no independent money available for field research.

Third, whatever research funding was available was largely tied to the research agendas of the burgeoning development industry. These were dominated by a 'developmentalist' paradigm and organised around international donor priorities (e.g. poverty, livelihoods, governance, NGOs, gender, sustainability, the environment and climate change) and limited to forms of economics-led social science. Much of the research was undertaken by foreign researchers with affiliations to development organisations, and was mostly 'applied' research, with local researchers in subordinate positions.

Searching for new ethnographic perspectives on the Bangladesh state now is timely because all this has changed substantially in recent decades. International aid has come to play a far smaller role in the economy, with less power to determine research agendas (although it still does). With more independent money, better international connections, and higher 
educational ambitions, it has become possible for growing numbers of young Bangladeshis to get access to higher education abroad. Many returned to do ethnographic research in Bangladesh, resulting in PhD theses, articles and monographs. Bangladeshi scholarly voices were emancipating themselves and today Bangladeshi ethnographers form a critical mass, capable of challenging the dominance of developmentalist research agendas and formulating their own research priorities. In a new transnational dialogue about the Bangladesh state, Bangladeshi ethnographers are setting new goals.

This process is facilitated by the fact that anthropology has become a subject that is taught more widely in Bangladesh, with better educated faculty and large numbers of anthropology graduates. They find jobs in different sectors, although many are still entangled in development agencies and careers. Crucially, anthropology students these days tend to be from middle-class rather than elite backgrounds, and there are different trajectories of knowledge production. As a result, there is a considerable and diverse group of people who can challenge the Bangladesh state's narrative about itself.

\section{Themes and questions from the articles}

In offering these concluding comments, we reflect on what has been (un)covered in these articles in order to set out an agenda of broader questions. In particular, what should be our frame of reference for studying the Bangladesh state, and how might we begin to think about how insights that emerge from studying ethnographically can contribute to state theory more widely?

Returning to the differences between the Bangladesh state and its immediate South Asian neighbours, an important starting point for analysis is the fact we encounter a state that rules over a majoritarian society supported by a particularly fervent nationalist ideology that is broadly shared by much of the population. This state ideology remains dominant and continues to have mobilising effects across a wide cross section of the population. But at the same time, its spread is increasingly uneven. For example, it does not necessarily hold among Bangladeshi migrants in India, many of whom quickly leave it behind (Ramachandran, 1999; Moodie, 2010).

Nor can the state in Bangladesh be fully understood without taking into account its distinctive double history of rupture, in 1947 and 1971. Emancipation from British colonial rule was followed by Pakistani colonial rule and a relatively late achievement of independence. These two distinct moments of decolonisation have each produced different sets of longer term effects, leaving Bangladesh different from other states and out of step with the rest of the post-colonial world. When Asian and African leaders met in Bandung in 1955 at the inception of what would become the non-aligned movement, Bangladesh did not yet exist. It did not therefore experience this moment of post-colonial consciousness, nor did it go on to encounter the subsequent waning of the post-colonial dream that later turned dystopic. Bangladesh was a latecomer to these shifts, experiencing its 'moment of hope' instead in the 1970s, in very different circumstances, having to come to terms with Western political ascendency resulting from development aid flooding in at the height of the Cold War. This trajectory distinguishes 
the Bangladesh state from other states in South Asia but invites comparisons with other latecomers that experienced a two-step decolonisation, such as Timor-Leste and South Sudan. This is also a state in which issues of ethnic and religious difference have been pushed to the margins. Unlike the rest of South Asia, Bangladesh has no active secessionist movements.

Yet despite its cohesiveness, and the relatively recent growth of a national self-confidence, Bangladesh's recent past remains unsettled. Such is the rawness of this history that it is not possible to speak of the Pakistan period today in Bangladesh without blame being attached to various people. This may be one of the factors contributing to the state's insecurity and paranoia that is visible in some of our articles (e.g. Mookherjee and Lacy, this volume).

Bangladesh's political system is more distinctive than is allowed for by simple regional comparisons. General Ershad's fall in 1990 marked the end of military rule - with the exception of the brief 2007-8 military-backed caretaker-government period - and since then a two party system has been in place. For most of the post-1990 period it has managed to deliver a relatively stable form of government. It is based on the colonial electoral system, with a 'first past the post' winner-takes-all structure - which remains present also in federated multi-ethnic Pakistan and India - but in Bangladesh the two-party system has operated differently and blocked opportunities for coalition building. This suggests perhaps that we need to widen the comparative frame to include other states that may have similar types of two-party system. In this respect, comparison with countries such as Costa Rica or Paraguay rather than simply with India or Pakistan may be instructive.

In contrast to India and Pakistan, the state is relatively centralised and lacks a federated structure, which further limits the usefulness of traditional types of regional comparison and suggests comparisons with more centralised states such as Bhutan, Thailand, or the Netherlands. At the same time, the marked separateness and distinctiveness of the three districts of the Chittagong Hill Tracts (CHT) means that the state is not quite unitary either. Indeed, the CHT remains crucial to any understanding the Bangladesh state, as illustrated particularly by one of the contributions found in this volume. This shows how ethnographic work that pays attention to the CHT adds to our understanding not only of this part of the country but of the state more widely (Siraj, this volume). For example, security technologies that are tested by the militarised state (surveillance, policing, counterterrorism) in 'marginal' areas such as CHT may later become significant for the rest of the country. The army's position within the state partly depends on its access such laboratory areas for testing these new technologies.

The authors in this volume provide new ethnographic insights into the Bangladesh state, while also generating further questions.

First, the political system has been changing in significant ways. A tipping point may be approaching in which stable political parties that have previously relied on charismatic leadership may soon no longer be able to do so. There are few signs that the opposition Bangladesh National Party (BNP) will be able to recover its lost ground, and as a result the 
era of the two-party system may now be drawing to a close. We are on the brink of a new politics, perhaps based around a form of one-party democracy.

Second, the state's trajectory of late decolonisation requires us to understand a slow historical process that is still unfolding, where post-colonial states continue both to come into being and fall apart. In this regard, comparisons between Bangladesh and other newly-formed postcolonial states with small elites, who have little experience of governing, may be fruitful. The idea of the state as work in progress is important here, and ethnographic accounts are effective at depicting the state as being 'in the making' rather than simply 'being there'. Ethnographic approaches also illuminate its improvised and often chaotic nature, belying the idea that there is a clear plan, or a thought-out long-term strategy, or indeed a conspiracy. At the same time, more work is needed to understand what has made the state remarkably resilient, at least in certain ways. For example, the reluctance of the army to take power after the fall of General Ershad has given parliamentary democracy a resilience that had not been apparent during the 1970s. However, such resilience has not developed evenly across the different areas of the state. For example, some sections of the new governing elite generated extremely high levels of competence through learning by doing, for example in Planning Commission and army, but this was perhaps less visible in other areas such as the diplomatic service.

Third, we note that the power of recent history to shape understandings of the state remains very strong, leading to absences and gaps. For example, experiences of the Partition of 1947 have been largely erased within dominant narratives of the state and are not easily discussed in today's Bangladesh. Instead, prominence is given to heroic nationalist accounts of 1971 in which the majority of the nation stood up to Pakistan, driven by political activism and the demand for democracy, with only a few traitorous dissenters. The narrative obscures the fact that there were many more people than is usually acknowledged who remained uncommitted at least until the last minute. This dominant local understanding of history inevitably suffuses the climate in which social science research is conducted and impacts upon understandings of the state.

\section{Where to go from here?}

An ethnographic approach can illuminate various dimensions of the Bangladesh state. We expect that it will be especially helpful in advancing deeper insight into the following themes:

\section{- Developmentalism.}

There is a wealth of information about how outsiders have conceived of development in Bangladesh but very little on the distinctive variants of developmentalism to which Bangladesh state agents subscribe, and how these variants vary and evolve. An ethnographic exploration at different levels of the Bangladesh state is the best way to map these ideological aspects.

\section{- Welfare.}

International neoliberal ideologies have caused welfare in Bangladesh to be substantially privatised in some ways - but not in others. Giant non-government organisations, such as 
Grameen and BRAC, emerged to provide country-wide health, safety-net, credit and educational services that were previously considered the domain of the state. An expansion of state social welfare services is key to the way in which the state currently seeks to secure its legitimacy, and ethnographic studies could delve into this expansion. There is a paradox in that many developers commonly characterise such welfare schemes as failing, even though they are really 'succeeding', as Hossain's recent work suggests (2017).

\section{- Financialisation.}

The study of the circulation of capital is woefully underdeveloped, despite some work in relation to microfinance and NGOs (e.g. Muhammad, 2015). How and when do Bangladesh state agents resist, facilitate, or serve capital flows? And how does capital actually percolate through the state system, shaping it in its wake? How is financial accountability organised? Such complex, obscure and sensitive relationships are best studied ethnographically.

\section{- Environment.}

The interface between state action and environmental issues is especially amenable to ethnographic approaches. There is an expanding arena of organised environmental resistance against the state, as movements against coal mining, shrimp farming, river and air pollution, and threats to the Sundarbans mangrove forest demonstrate. Environment and financialisation intersect in how the Bangladesh state deals with foreign corporations. Gardner (2012) shows that the state may resist foreign corporations in relation to gas extraction in ways that run counter to some expectations of the penetrative power of international capital. At the same time, the Bangladesh state has facilitated some foreign corporations, for example, from India.

\section{- Security.}

The role of the armed forces in the Bangladesh state is often speculated about but in the public domain fine-grained research-based analysis is almost completely absent. The ethos, culture and political roles of armed state agents (military, paramilitary, police, etc.) form an important field of study to be developed ethnographically. How and when do politicians and bureaucrats use their discretionary power to deploy security personnel in the domestic arena? And how does the state use private global security companies to provide unobtrusive 'security solutions' in the service of the state, and for the protection of new gated communities for the elites? ${ }^{3}$

\section{- Gender and kinship.}

How is the state organised in terms of gender and kinship? In this special issue we have several accounts of masculinity and leadership. How is the Bangladesh state gendered? And what has it done for the state to have had thirty years of female leadership? This can be studied domestically as well as by considering the extent to which the 'battling Begums' narrative has served to delegitimise the way Bangladesh is seen internationally. Kinship is another important theme, if we wish to understand the Bangladesh state. Family connections,

\footnotetext{
${ }^{3}$ For example, C4S (https://www.g4s.com/en-bd).
} 
political dynasties and kin alliances are clearly in evidence but have rarely been analysed ethnographically (but see Sabur $(2010 ; 2014)$ on marriage strategies among members of the oligarchy).

\section{- Regional variation.}

The articles in this special issue show that the Bangladesh state is not unitary, simple, or known. The ethnographic approach reveals significant spatial differences in the local manifestations of the state. The Bangladesh state operates differently in transnationally connected rural Sylhet (Hoque, this issue), in the militarised Chittagong Hill Tracts (Siraj, this issue), and in district towns (Kuttig and Ruud, this issue). It appears to have different faces in metropolitan Dhaka and 'middle' or 'provincial' Bangladesh (Schulz, and Mookherjee and Lacy, and Ruud, this issue). Residents of border regions - where space is more 'sensitive' (Cons (2016)) - experience it in another way. The state is unevenly strewn across the national territory, and state agents display locally specific behaviour. Here the state is continually shaped and refashioned by interactions between local society and state employees. Such interactions provide fertile ground for researchers with an ethnographic eye.

\section{[Editors: Please remove this dotted line. We were unable to do so]}

- The state beyond the national territory.

Ethnography of the Bangladesh state as an actor on the international scene is long overdue. How do state agents project images and narratives of the Bangladesh state abroad? What transnational soft and hard power does the Bangladesh state possess? Which extra-local alliances does it engage in, and which transnational friends, foes and threats does it identify? Why has it become such an important provider of peacekeeping personnel for the United Nations? How do different state institutions cope with cross-border issues such as the Rohingya influx of 2017? In addition, ethnographic scrutiny of the policies of the Bangladesh state (and, indeed, political parties) regarding Bangladeshi diasporic communities around the world could help explore the state's global aspirations.

\section{- Boundaries between state and non-state realms.}

Understanding where the state begins and ends is a subject touched upon by some of the articles in this collection. Boundaries are both ambiguous and productive, making them subjects ripe for more detailed ethnographic study. For example, encounters between governmental and non-governmental actors, and forms of boundary spanning work undertaken by individuals and groups that connect the state to non-state realms, remain comparatively underexplored.

\section{- The state and its citizens.}

One of the dimensions that ethnographic research can illuminate very well is the relationship between the Bangladeshi state and the population over which it rules. Is this a relationship that retains elements of the colonial state from which it developed? Can it be characterised as a neo-colonial state? Do state agents treat individual Bangladeshis as citizens, or rather as subjects? How do Bangladeshis imagine the state and how do they experience and perceive its 
judicial, executive and legislative powers, and the degree to which these are separate (see Schulz and Berger, this issue)?

- State or nation.

Finally, how does the idea of the state relate to the nation? There are many moments of pride for Bangladeshis: when the cricket team wins, when a mountaineer reaches the top of a peak, or when the United Nations peacekeepers win over people in Sierra Leone. But is it the nation or the state that is being celebrated? And what about moments of conflict and hurt (e.g. the events at Shahbag in 2013), when the Bangladesh state and different fragments of the nation can be seen to clash? The meeting points of state and nation can best be scrutinised in ethnographies of state-nation interactions.

In this brief postscript we have made the case for intensifying efforts to understand the Bangladesh state ethnographically, and we have sketched out some possible directions for such future work, recognising of course that there may be many more than we have listed here. We suggest that this should be seen as a relatively new field of study for scholars of Bangladesh, but we also draw attention to a wide and diverse body of literature from which those taking forward this new agenda (including the contributors to this special issue) can draw inspiration in future work. 


\section{References}

Adnan, Shapan. 1989. Annotation of Village Studies in Bangladesh and West Bengal: A Review of Socio-Economic Trends over 1942-88. Kotbari: Bangladesh Academy for Rural Development.

Ali, Md. Bosharot. 2011. Purbo Banglar Gramin Orthoniti, Shomaj O Shongskriti (1923-43): Md. Bosharot Alir Dinponji [The Village Economy, Society and Culture of East Bengal (1923-43): Md. Bosharot Ali's Diary]; ed. by Md. Mahbubar Rahman. Dhaka: Asiatic Society of Bangladesh.

Ali, Tariq Omar. 2018. A Local Global History of Global Capital: Jute and Peasant Life in the Bengal Delta. Princeton and Oxford: Princeton University Press, 2018.

Arens, Jenneke, and Jos van Beurden. 1977. Jhagrapur: Poor Peasants and Women in a Village in Bangladesh. Birmingham: Third World Publications.

Arens, Jenneke. 2014. Women, Land and Power in Bangladesh: Jhagrapur Revisited. Dhaka: University Press Limited.

Beames, John. 1961. Memoirs of a Bengal Civilian. London: Chatto and Windus.

Bernot, Lucien. 1967. Les paysans arakanais du Pakistan Oriental: le monde végétal et l'organisation sociale des réfugiés Marma (Mog) [Arakanese Peasants of East Pakistan: Social Organisation of the Marma (Mog) Refugees]. Paris and The Hague: Mouton, 2 vols.

Bertocci, Peter J. 1970. 'Elusive Villages: Social Structure and Community Organization in Rural East Pakistan'. PhD Thesis. East Lansing, Mich.: Michigan State University.

Bessaignet, Pierre, ed. 1960. Social Research in East Pakistan. Dhaka: Asiatic Society of Pakistan.

BRAC. 1979. Who Gets What and Why? Resource Allocation in a Bangladesh Village. Rural Study Series 1. Bangladesh Rural Advancement Committee. Dhaka: Bangladesh.

BRAC. 1980. The Net: Power Structure in Ten Villages. Bangladesh Rural Advancement Committee. Dhaka: Bangladesh.

BRAC. 2006. The State of Governance in Bangladesh. Centre for Governance Studies, BRAC University and BRAC Research \& Evaluation Division. Dhaka: Bangladesh.

Buchanan, Francis. 1833. A Geographical, Statistical and Historical Description of the District, or Zila, of Dinájpur, in the Province, or Soubah, of Bengal. Calcutta: Baptist Missionary Press. 
Buchanan, Francis. 1992. Francis Buchanan in Southeast Bengal (1798): His Journey to Chittagong, the Chittagong Hill Tracts, Noakhali and Comilla; ed. by Willem van Schendel. Dhaka: University Press Limited.

Chaudhuri, Nirad C. 1951. The Autobiography of an Unknown Indian. London: Macmillan Company.

Cons, Jason. 2016. Sensitive Space: Fragmented Territory at the India-Bangladesh Border. Seattle and London: University of Washington Press.

Den Hollander, A.N.J. 1955/1990. 'Sociale beheersing in een Bengaalse stad: de "mahalla sardars" en "panchayats" van Dacca, Oost Pakistan' [Social control in a city in Bengal: the 'mahalla sardars' and 'panchayats' of Dacca, East Pakistan] (Willem van Schendel, trans., Khwaja Mahomed Azam, ed.) The Panchayat System of Dhaka. Dhaka: Dhaka City Museum.

Ellickson, Jean. 1973. 'A Believer Among Believers: The Religious Beliefs, Practices, and Meanings in a Village in Bangladesh'. PhD thesis. East Lansing, Mich.: Michigan State University.

Gardner, Katy. 2012. Discordant Development: Global Capitalism and the Struggle for Connection in Bangladesh. London: Pluto Press.

Hara, Tadahiko. 1991. Paribar and Kinship in a Moslem Rural Village in East Pakistan. Tokyo: Institute for the Study of Languages and Cultures of Asia and Africa.

Hartmann, Betsy, and James K. Boyce. 1983. A Quiet Violence: View from a Bangladesh Village. London: Zed Press.

Hossain, Naomi. 2010. 'Rude Accountability: Informal Pressures on Frontline Bureaucrats in Bangladesh.' Development and Change, 41:5: 907-28.

Hossain, Naomi. 2017. The Aid Lab: Understanding Bangladesh's Unexpected Success. Oxford: Oxford University Press.

Iqbal, Iftekhar. 2010. The Bengal Delta: Ecology, State and Social Change, 1840-1943. London: Palgrave Macmillan.

Iqbal, Iftekhar. 2018. 'State of (the) Mind: The Bengali Intellectual Milieu and Envisioning the State in the Post-Colonial Era', South Asia: Journal of South Asian Studies, 41:4: 876-91.

Jack, J.C. 1916. The Economic Life of a Bengal District: A Study. Oxford: Clarendon. 
Jahangir, Burhanuddin Khan. 1979. Differentiation, Polarisation and Confrontation in Rural Bangladesh. Dhaka: Centre for Social Studies.

Jansen, Eirik G. 1986. Rural Bangladesh: Competition for Scarce Resources. Oslo: Norwegian University Press.

Jansen Eirik G. 2019. Seeing the End of Poverty? Bhairama Revisited. Dhaka: University Press Limited.

Kamal, Ahmed. 2009. State Against the Nation: The Decline of the Muslim League in PreIndependence Bangladesh, 1947-54. Dhaka: University Press Limited.

Khan, Mushtaq. 2014. 'Aid and Governance in Vulnerable States: Bangladesh and Pakistan since 1971'. The Annals of the American Academy of Political and Social Science, (656) 1: $59-78$.

Lewin, Thomas Herbert. 1912. A Fly on the Wheel, or, How I helped to Govern India. London: Constable \& Company Ltd.

Lewis, David. 2011. Bangladesh: Politics, Economy and Civil Society. Cambridge: Cambridge University Press.

Lewis, David, and Abul Hossain. 2019. 'Local Political Consolidation in Bangladesh: Power, Informality and Patronage', Development \& Change.

https://onlinelibrary.wiley.com/doi/epdf/10.1111/dech.12534

Machell, Thomas. 1840-1856. 'Journals of Thomas Machell'. India Office Private Papers, Mss Eur B369, British Library, London, 5 volumes.

Mahmud, Wahiduddin, Ahmed, Sadiq, Mahajan, Sandeep. 2008. Economic Reforms, Growth, and Governance: The Political Economy Aspects of Bangladesh's Development Surprise. Washington, DC: World Bank.

Mazumdar, Shudha. 1977. A Pattern of Life: The Memoirs of an Indian Woman; ed. by Geraldine Forbes. New Delhi: Manohar.

Mey, Wolfgang. 1980. Politische Systeme in den Chittagong Hill Tracts, Bangla Desh [Political Systems of the Chittagong Hill Tracts, Bangladesh]. Bremen: Übersee-Museum.

Mitton, Keiran. 2018. Working paper summary of the first LSE-UC Berkeley Bangladesh Summit, June 5, London School of Economics. http://www.lse.ac.uk/south-asiacentre/assets/documents/WorkingPapers/Bangladesh-Papers-3-2.pdf 
Moodie, Megan. 2010. “"Why Can’t You Say You Are from Bangladesh?”: Demographic Anxiety and Hindu Nationalist Common Sense in the Aftermath of the 2008 Jaipur Bombings'. Identities: Global Studies in Culture and Power, 17:5: 531-59.

Muhammad, Anu. 2015. 'Bangladesh - A Model of Neoliberalism'. Monthly Review Press, 66(10): 35-46.

Mukherjee, Ramkrishna. 1971. Six Villages of Bengal. Bombay: Popular Prakashan.

Orr, Alastair. 2012. 'Why were So Many Social Scientists Wrong about the Green

Revolution? Learning from Bangladesh'. Journal of Development Studies, 48(11): 1565-86.

Owen, J.E., ed. 1962. Sociology in East Pakistan. Dhaka: Asiatic Society of Pakistan.

Qadir, S.A. 1960. Village Dhanishwar: Three Generations of Man-Land Adjustment in an East Pakistan Village. Comilla: Pakistan Academy for Rural Development.

Ramachandran, Sujata. 1999. 'Of Boundaries and Border Crossings: Undocumented Bangladeshi "Infiltrators" and the Hegemony of Hindu Nationalism in India'. Interventions International Journal of Postcolonial Studies, 1:2: 235-53.

Rashid, Saifur, and Hasan A. Shafie. 2017. 'Situating Anthropology in Bangladesh:

Transformations and Trajectories in the Anthropology Tradition'.

http://www.lectitopublishing.nl/Article/Detail/6JZU96DR

Report of the Indigo Commission, 1860: Report, Minutes of Evidence and Appendix. Calcutta, 1860-61.

Sabur, Seuty. 2010. 'Mobility Through Affinal Relations: Bangladeshi "Middle Class", Transnational Immigrants and Networking'. PhD Thesis, National University of Singapore.

Sabur, Seuty. 2014. 'Marital Mobility in the Bangladeshi Middle Class: Matchmaking Strategies and Transnational Networks'. South Asia: Journal of South Asian Studies, 37:4: 586-604.

Saqui, Q. Md. Afsar Hossain, and Khaleda Akhtar. 1987. Village Studies in Bangladesh: An Annotated Bibliography. Dhaka: National Institute of Local Government.

Siddiqui, Kamal. 1994. Local Government in Bangladesh. Third edition. Dhaka: University Press Limited.

Siddiqui, Kamal. 2000. Jagatpur, 1977-97: Poverty and Social Change in Rural Bangladesh. Dhaka: University Press Limited. 
Sharma, Aradhana, and Akhil Gupta. 2006. 'Introduction: Rethinking Theories of the State in An Age of Globalization'. In The Anthropology of the State: A Reader, edited by Sharma, Aradhana Sharma and Akhil Gupta, 1-43. Oxford: Blackwell.

Thorp, John P. 1978. Power Among the Farmers of Daripalla: A Bangladesh Village Study. Dhaka, Bangladesh: Caritas.

Van Schendel, Willem. 1981/82. Peasant Mobility: The Odds of Life in Rural Bangladesh. Assen: Van Gorcum/Delhi: Manohar Books.

Van Schendel, Willem. 1995. Reviving a Rural Industry: Silk Producers and Officials in India and Bangladesh, 1880s to 1980s. Dhaka: University Press Limited / Delhi: Manohar Publishers.

Westergaard, Kirsten. 1980. Boringram: An Economic and Social Analysis of a Village in Bangladesh. Bogra: Rural Development Academy.

Westergaard, Kirsten, and Abul Hossain. 2005. Boringram Revisited: Persistent Power Structure and Agricultural Growth in a Bangladesh Village. Dhaka: University Press Limited.

White, Sarah C. 1992. Arguing with the Crocodile: Gender and Class in Bangladesh. London: Zed Books.

Wise, James. 1883. Notes on the Races, Castes and Trades of Eastern Bengal. London: Her Majesty's Printer Harrison and Sons.

Wood, Geof. 2018. 'Deconstructing the natural state? Is There Room For De Toqueville or Only Gramsci in Bangladesh?' In Politics and Governance In Bangladesh: Uncertain Landscapes, edited by Ipshita Basu, Joe Devine and Geof Wood, 107-124. London: Routledge.

Zaidi, S.M. Hafeez. 1970. The Village Culture in Transition: A Study of East Pakistan Rural Society. Honolulu: East-West Center Press.

Zaman, Shahaduz. 2005/2017. Broken Limbs, Broken Lives: Ethnography of a Hospital Ward in Bangladesh. PhD thesis, University of Amsterdam/Dhaka: University Press Limited. 